\title{
Effects of seed bank disturbance on the fine-scale genetic structure of populations of the rare shrub Grevillea macleayana
}

\author{
PR England ${ }^{1}$, RJ Whelan and DJ Ayre \\ Institute for Conservation Biology, Department of Biological Sciences, University of Wollongong, NSW 2522, Australia
}

\begin{abstract}
Dispersal in most plants is mediated by the movement of seeds and pollen, which move genes across the landscape differently. Grevillea macleayana is a rare, fire-dependent Australian shrub with large seeds lacking adaptations for dispersal; yet it produces inflorescences adapted to pollination by highly mobile vertebrates (eg birds). Interpreting finescale genetic structure in the light of these two processes is confounded by the recent imposition of anthropogenic disturbances with potentially contrasting genetic consequences: (1) the unusual foraging behaviour of exotic honeybees and 2. widespread disturbance of the soil-stored seedbank by road building and quarrying. To test for evidence of finescale genetic structure within $G$. macleayana populations and to test the prediction that such structure might be masked by disturbance of the seed bank, we sampled two sites in undisturbed habitat and compared their genetic
\end{abstract}

structure with two sites that had been strongly affected by road building using a test for spatial autocorrelation of genotypes. High selfing levels inferred from genotypes at all four sites implies that pollen dispersal is limited. Consistent with this, we observed substantial spatial clustering of genes at $10 \mathrm{~m}$ or less in the two undisturbed populations and argue that this reflects the predicted effects of both high selfing levels and limited seed dispersal. In contrast, at the two sites disturbed by road building, spatial autocorrelation was weak. This suggests there has been mixing of the seed bank, counteracting the naturally low dispersal and elevated selfing due to honeybees. Pollination between near neighbours with reduced relatedness potentially has fitness consequences for $G$. macleayana in disturbed sites.

Heredity (2003) 91, 475-480. doi:10.1038/sj.hdy.6800308

Keywords: spatial autocorrelation; microsatellites; disturbance; seed dispersal

\section{Introduction}

Characterising gene flow and structure at the finest scale within populations is critical to understanding how broader scale genetic patterns are generated. Fine-scale structure promotes the generation of novel genotypes locally, promoting evolution (Wright, 1969). Fine-scale structure and habitat patch size and shape can interact to affect the rate of accumulation of deleterious mutations (Kawata, 2001). It is also important to identify when intrapopulation structure exists because this can compromise the validity of population genetic analyses that assume homogeneity, such as estimates of gene frequencies, heterozygosity, Hardy-Weinberg proportions and outcrossing rates. Sampling strategies designed to measure these parameters and to conserve genetic biodiversity also require the delineation of fine-scale genetic structure.

There is a burgeoning of interest in the study of gene flow at local scales that is being fueled by recent advances in genetic and statistical methodologies (Lui-

Correspondence: PR England, Institute for Conservation Biology, Department of Biological Sciences, University of Wollongong, NSW 2522, Australia. E-mail: pengland@cafepeng.com

${ }^{1}$ Current address: Laboratoire d'Ecologie Alpine, Université Joseph Fourier, BP 53-38041, Grenoble cedex 9, France.

Received 3 April 2002; accepted 4 April 2003 kart and England, 1999). Research is revealing that many systems exhibit structure at fine scales, but a detailed understanding of the biology of a species is often required to interpret the observed patterns with respect to the relative importance of short- and long-range dispersal mechanisms.

In plants, a combination of limited dispersal of seed and pollen has long been predicted to generate fine-scale genetic structuring (see simulations of Turner et al, 1982). However, empirical findings do not always match these predictions and theoretical work suggests that spatial autocorrelation should be lower than generally expected (Epperson, 1995). High levels of pollen flow and seed dispersal result in no detectable spatial genetic structure in lodgepole pine (Epperson and Allard, 1989) and, in Camellia japonica, the effects of low seed dispersal appear to have been ameliorated by overlapping seed shadows and high levels of pollen flow (Ueno et al, 2000). In contrast, Smouse et al (2001) found surprisingly small effective pollen dispersal neighbourhoods in Quercus alba, which has been assumed to have widely dispersing pollen. Bonnin et al (2001) demonstrated substantial finescale structure in the highly selfing Medicago truncatula.

Grevillea macleayana (family Proteaceae) is a rare shrub (Briggs and Leigh, 1996) that has a restricted and fragmented distribution in south-eastern New South Wales (McGillivray, 1993; Makinson, 1999). It has been the focus of numerous ecological and genetic studies 
(reviewed in Whelan et al, 2000). The species is pollinated by a range of bird species and introduced honeybees (Apis mellifera), it is fully self-compatible, capable of seed set by autogamy (Vaughton, 1995) and outcrossing rates appear to vary dramatically among populations (Ayre et al, 1994; England et al, 2001). Although plants are killed by fire, populations persist by recruitment from a soilstored seed bank, following breaking of dormancy by fire or soil disturbance (Edwards and Whelan, 1995). Seeds have no obvious adaptations that would facilitate seed dispersal.

Like many species in the family Proteaceae, G. macleayana shows obvious adaptations for bird pollination (Makinson, 1999). Its numerous inflorescences are large, colourful and nectar-laden. Its pollinators are abundant and active (Vaughton, 1996) suggesting that pollen-mediated dispersal is important. However, several factors potentially limit the contribution of bird-mediated pollen movement to gene flow in G. macleayana. (1) The species is self-compatible and high contemporary selfing levels have been recorded in some populations (Ayre et al, 1994; England et al, 2001, 2002). (2) Seeds show no obvious adaptations for dispersal, instead lodging in soil (and presumably germinating) close to the mother plant (Edwards and Whelan, 1995). (3) Introduced honeybees appear to be disrupting pollination patterns by interfering with the role vertebrates may have formerly played as the primary pollen vector (England et al, 2001, 2002).

G. macleayana is an obligate seeder and populations naturally depend on fire to regenerate from the seed bank (Edwards and Whelan, 1995). Although G. macleayana has no obvious natural means of seed dispersal, its germination is readily triggered by habitat disturbance/soil movements presumably via seed coat scarification (Edwards and Whelan, 1995) and a substantial proportion of extant populations occur along roads and in gravel quarries. We postulated that soil disturbance may therefore promote genetic mixing within affected populations. Natural patterns of finescale structure are sensitive to anthropogenic disturbances associated with the exploitation of natural areas, such as road-building, quarrying and patchy forest clearance (McGarigal et al, 2001; Jackson et al, 2002; DeStephano, 2002). We have exploited the high resolution offered by microsatellites to investigate whether these effects are also detectable at the genetic level.

We tested for spatial genetic structure in G. macleayana populations using a new multilocus, multiallele method developed by Smouse and Peakall (1999). Until recently, genetic spatial autocorrelation, including tests that use Moran's I, necessarily utilised single-locus procedures. The genetic distance calculated by the method of Smouse and Peakall is a true multilocus measure that uses information from multiple loci simultaneously (see Smouse and Peakall, 1999) for a discussion of the relation among existing tests for spatial association of genotypes).

\section{Materials and methods}

We mapped the locations and determined the six-locus microsatellite genotypes of $G$. macleayana plants within four sites (Figure 1) according to the methods described in England et al (1999). Here we present expected heterozygosity, observed heterozygosity and fixation index with $95 \%$ confidence intervals generated by bootstrapping across loci (Table 1). See England et al (2002) for a more extensive population genetic analysis of these and other populations. Plants from two populations, Wright's Beach and Long Beach South, were sampled from along the edges of roads that had been constructed with heavy machinery. At Wright's Beach we sampled 20 plants bordering approximately $200 \mathrm{~m}$ of a more extensive population that extends several hundred metres further along the road. We sampled 28 plants at Long Beach South, comprising what appears to be the entire population in that locality. The roads at both sites were sloping and lined with earth mounds indicative of substantial soil disturbance. In many cases, plants were growing directly in the earth mounds or in drainage ditches. We have called these disturbed sites. The other two sites were in what appears to be relatively undisturbed habitat, although foot tracks exist in both sites and a sealed road borders the Hyam's Beach site (Figure 1). The Abraham's Bosom site, where we sampled all 31 mature plants, is in a flat open heathland with some low Eucalypt trees. The Hyam's Beach site is mostly in flat, low woodland with a dense understory. We sampled 23 plants at this site. Later investigation revealed that the population at this locality is substantially larger. We have called these "undisturbed sites", and we assume that they are closer to what may be described as the natural state.

We used the spatial autocorrelation method of Smouse and Peakall (1999), as implemented in the software package GenAlEx (Peakall and Smouse, 2001), to generate autocorrelelograms with $5 \mathrm{~m}$ size classes for each population out to a maximum distance of $50 \mathrm{~m}$. Beyond $50 \mathrm{~m}$ all populations began to exhibit empty size classes. We reasoned that $5 \mathrm{~m}$ was the maximum viable resolution because many plants had diameters approaching but not exceeding this size. Untransformed Euclidean distances were used.

Tests for statistical significance in GenAlEx were performed by random permutation. This consists of randomly shuffling the individual genotypes among the geographic locations and recomputing autocorrelation coefficient $r$. This generates a distribution of $r$ based on the null hypothesis of no spatial genetic structure from which the probability of the observed $r$ can be determined.

\section{Results}

All six loci were polymorphic at each site (England et al, 2002). Expected heterozygosity at the four sites was similar and all sites displayed highly significant heterozygote deficits. Fixation indices derived from heterozygosities were substantial at all sites (Table 1) and at only one site (Hyam's Beach) did the 95\% confidence intervals include zero).

\section{Spatial autocorrelation}

Multilocus correlellograms (Figure 2) show the autocorrelation coefficient, $r$, as a function of distance and the 95\% confidence interval about the null hypothesis of no spatial genetic structure. There are significant genetic correlations between individuals in the 5 and $10 \mathrm{~m}$ distance classes at the two undisturbed sites, Abraham's Bosom ( $P=0.017$ at $5 \mathrm{~m} ; P=0.004$ at $10 \mathrm{~m}$; Table 2$)$ and 
$\odot$ plant

- road

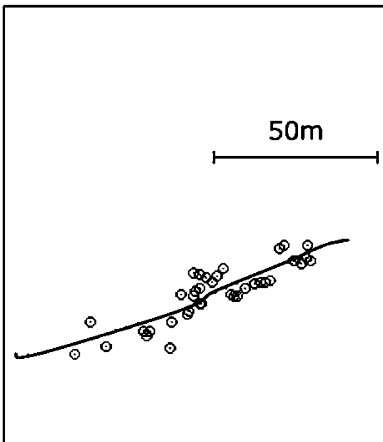

... foot track

WB
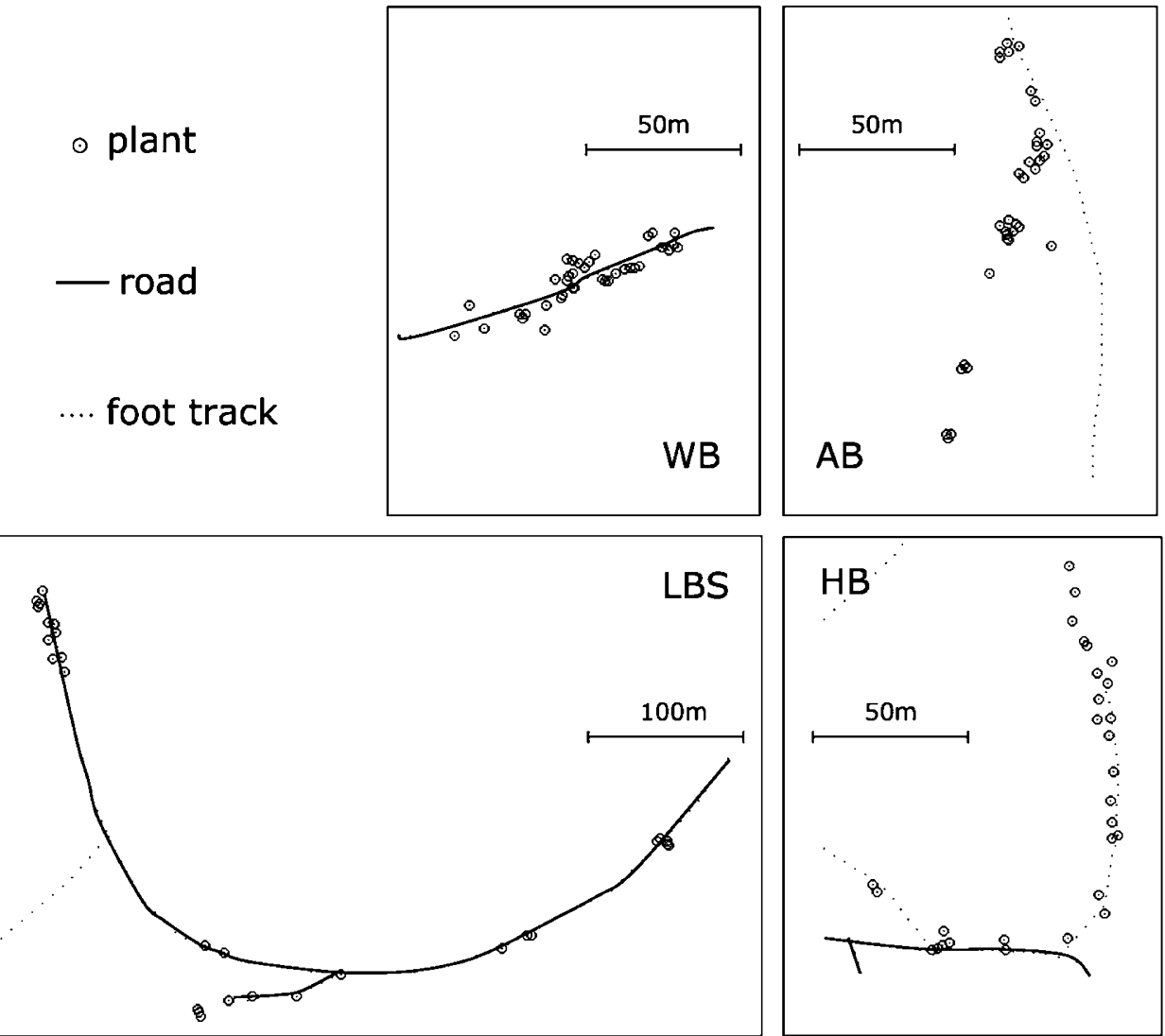

Figure 1 Sampled G. macleayana sites. AB, Abraham's Bosom, HB, Hyam's Beach, LBS, Long Beach South, WB, Wright's Beach.

Table 1 Expected heterozygosity $\left(H_{\text {exp }}\right)$, observed heterozygosity $\left(H_{\text {obs }}\right)$, fixation index $\left(F_{\mathrm{I}}\right)$ with bootstrapped $95 \%$ confidence intervals and mean sample sizes at the four sites (from England et al, 2002)

\begin{tabular}{|c|c|c|c|c|}
\hline & \multicolumn{2}{|c|}{ Undisturbed sites } & \multicolumn{2}{|c|}{ Disturbed sites } \\
\hline & Abraham's Bosom & Hyam's Beach & Long Beach South & Wright's Beach \\
\hline$H_{\exp }$ & 0.420 & 0.510 & 0.493 & 0.506 \\
\hline$H_{\text {obs }}$ & $0.248^{*}$ & $0.423^{*}$ & $0.358^{*}$ & $0.330^{*}$ \\
\hline$F_{\mathrm{I}}$ & $0.284(0.140,0.454)$ & $0.183(-0.002,0.382)$ & $0.223(0.040,0.407)$ & $0.309(0.118,0.484)$ \\
\hline$N$ & 28.0 & 19.2 & 27.7 & 19.0 \\
\hline
\end{tabular}

*Highly significant $(P<0.01)$ heterozygote deficit based on exact tests (Genepop 3.2).

Hyam's Beach $(P=0.001$ at $5 \mathrm{~m} ; P=0.007$ at $10 \mathrm{~m}$; Table 2). At greater distances, the correlation is contained within the $95 \%$ confidence boundaries except for a single point at $30 \mathrm{~m}$ at Abraham's Bosom. However, this correlation was not significant (Table 2). Plant genotypes in the $5 \mathrm{~m}$ class at Hyam's Beach were particularly highly correlated $(r=0.388)$. No correlation was apparent from the correlelograms at $5 \mathrm{~m}$ in the disturbed sites, Wright's Beach and Long Beach South. However, at Long Beach South, significant positive correlations were recorded at $10 \mathrm{~m}(P=0.035$, Table 2$)$ and $25 \mathrm{~m}(P=0.012$ Table 2$)$.

\section{Discussion}

A selfing plant species lacking obvious seed dispersal mechanisms might be expected to display high levels of genetic spatial autocorrelation. This is what we observed at the two undisturbed G. macleayana sites. We detected significant genetic correlations between near neighbours that appear to extend up to $10 \mathrm{~m}$. Significant spatial structure over this range is consistent with expectations based on reports of short seed dispersal distances (Edwards and Whelan, 1995) and high selfing rates (Ayre et al, 1994; England et al, 2001). Highly significant heterozygote deficits and substantial inferred fixation indices evident in adult plants suggests that selfing occurs or has occurred in the past at all four sites.

G. macleayana is not known to reproduce vegetatively; therefore short-range seed dispersal appears to be the primary cause of the observed fine-scale genetic structure. The scales at which significant spatial autocorrelation has been observed in genetic studies of 

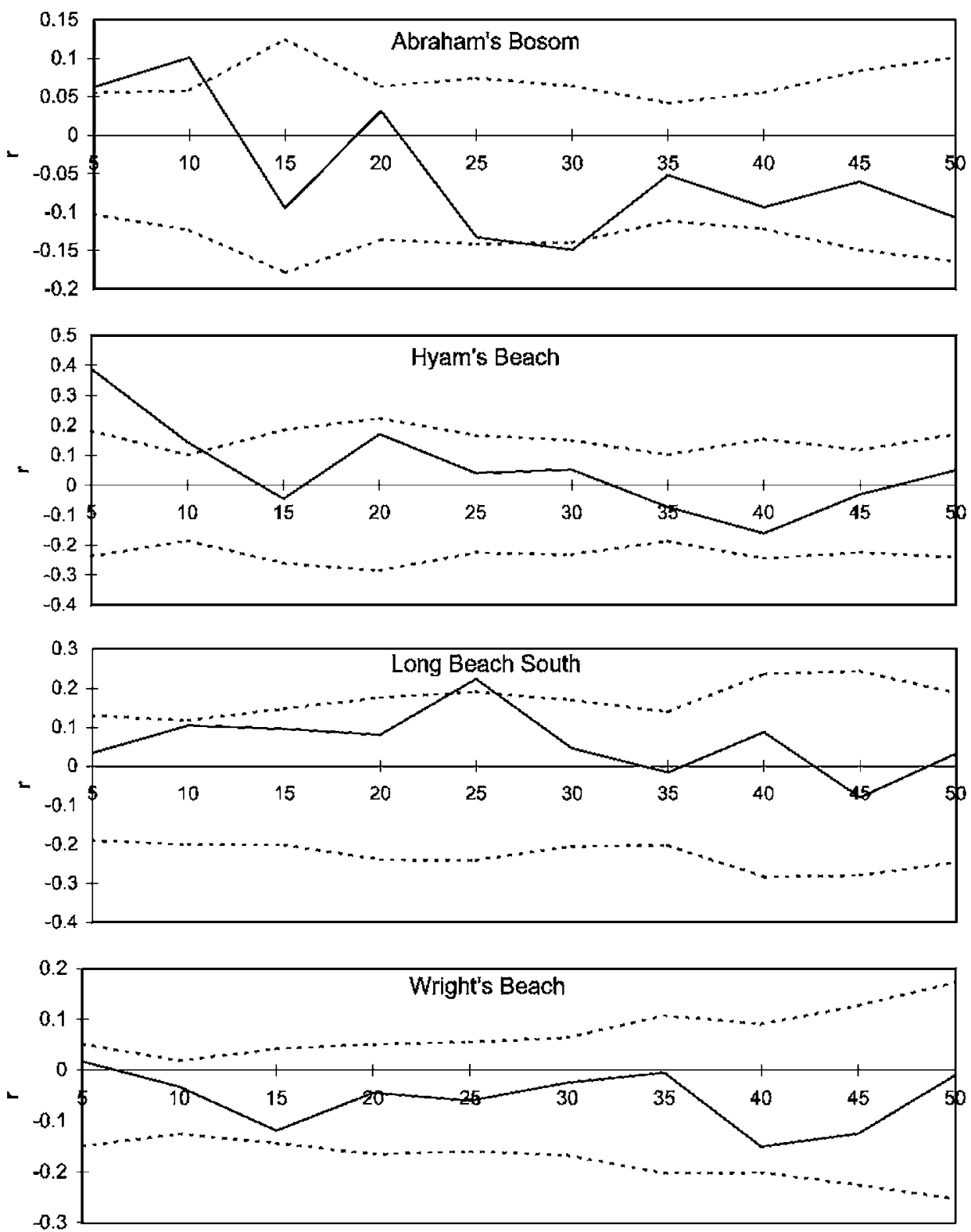

Distance $(m)$

Figure 2 Correlelograms of pairwise genetic distances between G. macleayana plants up to $50 \mathrm{~m}$ at $5 \mathrm{~m}$ intervals at four sites. Dashed lines encompass $95 \%$ of correlations permuted by randomising the spatial distribution of the genotypes at each size class.

nonvegetatively reproducing plants include $5 \mathrm{~m}$ in Ipomopsis aggregata (Campbell and Dooley, 1992), 3-7 m in Medicago truncatata (Bonnin et al, 2001), 5-10 $\mathrm{m}$ in Quercus laevis (Berg and Hamrick, 1995), $5 \mathrm{~m}$ in Psychotria officinalis, $<50 \mathrm{~m}$ in $Q$. robur and Q. petraea (Streiff et al, 1998), 1-2 $\mathrm{m}$ in Silene acaulis (Gehring and Delph, 1999) and $7 \mathrm{~m}$ in Caladenia tentaculata (Smouse and Peakall, 1999). In every case, limited seed dispersal was nominated as the primary causal factor.

Pollinator activity potentially opposes the factors promoting fine-scale structure in G. macleayana. Inflorescences are frequently visited by birds and some interplant movement occurs. However, vertebrate exclusion experiments in G. macleayana showed that birds made a surprisingly small contribution to pollination among plants in the presence of introduced honeybees (England et al, 2001). This is likely to lower the capacity of pollen dispersal to erase fine-scale structure due to low seed dispersal.

Fixation indices inferred from heterozygote deficits were high in many populations, suggesting that periods of high selfing are common (England et al, 2002). In the light of our present findings, that is, that some populations display significant substructuring, estimates of outcrossing reported in previous studies in G. macleayana need to be treated with caution because the direct and indirect methods used to estimate outcrossing assume spatial homogeneity of alleles within populations. 
Table 2 Probabilities that $r$ >permuted $r$ from spatial autocorrelation analyses of microsatellite genetic distances between individuals of $G$. macleayana at euclidean distances up to $50 \mathrm{~m}$ across all loci

\begin{tabular}{|c|c|c|c|c|c|c|c|c|c|c|c|}
\hline \multirow[t]{2}{*}{ Population } & & \multicolumn{10}{|c|}{ Distance (m) } \\
\hline & & 5 & 10 & 15 & 20 & 25 & 30 & 35 & 40 & 45 & 50 \\
\hline \multicolumn{12}{|l|}{ Abraham's Bosom } \\
\hline & $P$ & $0.017^{*}$ & $0.004^{*}$ & 0.767 & 0.087 & 0.962 & 0.987 & 0.669 & 0.902 & 0.669 & 0.849 \\
\hline & $n$ & 41 & 30 & 11 & 23 & 21 & 23 & 36 & 27 & 17 & 13 \\
\hline \multicolumn{12}{|l|}{ Hyam's Beach } \\
\hline & $n$ & 7 & 15 & 6 & 5 & 8 & 9 & 14 & 8 & 10 & 8 \\
\hline \multicolumn{12}{|l|}{ Long Beach South } \\
\hline & $P$ & 0.198 & $0.035^{*}$ & 0.072 & 0.153 & $0.012^{*}$ & 0.191 & 0.410 & 0.176 & 0.595 & 0.258 \\
\hline \multirow{3}{*}{ Wright's Beach } & $n$ & 10 & 10 & 9 & 6 & 6 & 8 & 9 & 4 & 4 & 6 \\
\hline & $P$ & 0.098 & 0.300 & 0.929 & 0.430 & 0.560 & 0.310 & 0.253 & 0.905 & 0.799 & 0.349 \\
\hline & $n$ & 23 & 42 & 28 & 22 & 19 & 20 & 10 & 10 & 9 & 5 \\
\hline
\end{tabular}

* Significant autocorrelation $(P<0.05) . n$ is the number of pairwise comparisons in each distance class.

Spatial structure in disturbed populations

At the sites characterised by disturbance associated with road building and roadside drainage (Long Beach South and Wright's Beach), spatial autocorrelation was substantially reduced or absent over short distances. This result is consistent with there having been mixing of the seed bank at disturbed sites, resulting in increased seed dispersal and a breakdown of spatial association of genotypes. The genetic composition of the populations at all four sites was similar, implying that seedbanks from which these populations arose were the product of similar levels of selfing. It is just the distribution of adult genotypes that is different. It is apparent at both of the disturbed sites that substantial earth movement has occurred, with large mounds bordering the roads. Seeds have potentially been moved many metres by the construction and maintenance methods used. Scarification of the seed coat, likely to accompany soil disturbance, is known to trigger germination in G. macleayana (Edwards and Whelan, 1995). This may explain the prevalence of G. macleayana plants along roads and in gravel quarries. Further, extremely large volumes of water have been observed flowing in the gutters beside roads in the vicinity of our study. Soil and any seeds it contains are potentially moved long distances by this process.

A similar phenomenon was reported in the selfing annual $M$. truncatula, in which the absence of fine-scale structure in one population was attributed to the annual ploughing that occurs at the site and the consequent mixing of the soil seed bank (Bonnin et al, 2001). The two undisturbed sites in that study exhibited fine-scale genetic structure.

An alternative explanation for the absence of fine-scale structure at the disturbed sites is that road building has triggered the germination of multiple seed cohorts (found deeper in the soil) that would not normally be recruited after fire-triggered germination. This mixing of seedbanks from number of earlier generations with different spatial distributions might diminish, through superimposition, any signal of fine-scale structure associated with each generation.
It is possible that the negative correlation between disturbance and fine-scale structuring is coincidental, representing sampling effect in a naturally variable set of populations. However, the consistent results over two undisturbed and two disturbed populations suggest a robust finding that could be tested in a larger-scale study. Alternative explanations for the absence of structure in roadside populations might include differences in natural selection at the two types of sites, although the nature of such a difference is difficult to envisage. Selection is expected to retard the development of spatial structure by maintaining (or excluding) certain variants in a population. This effect might be evident at neutral loci through hitchhiking of alleles with regions under selection and this effect is accentuated in selfing species.

\section{Evolutionary genetic implications}

A substantial proportion of recorded populations of $G$. macleayana occur in disturbed areas including roads, gravel quarries, a municipal dump and a defence force bombing range. Extremely high natural predation of the seed bank (78-100\%, Vaughton, 1998) and dependence on fire for germination suggests that population persistence is naturally quite tenuous and unpredictable. Opportunistic germination due to anthropogenic disturbance may therefore be generating an unnatural distribution of populations in some areas. If the negative correlation we have observed between disturbance and fine-scale genetic structure is indeed causal, our result potentially has nontrivial and possibly positive consequences for this rare species. For example, dispersal of seeds may reduce the proportion of consanguineous matings normally caused by pollen flow among related neighbours. In species that experience inbreeding depression, this might increase mean fitness levels. Experiments are planned to test whether G. macleayana suffers inbreeding depression.

Our finding that undisturbed populations possess finescale structure has implications for genetic research and ongoing monitoring of G. macleayana populations. The existence of structure contravenes the assumption of 
random dispersal of genotypes that underlies the estimation of parameters such as gene frequencies in adult plants and the pollen cloud, direct and indirect outcrossing rates and Hardy-Weinberg proportions. Such estimates should therefore be treated with caution in the future.

\section{Acknowledgements}

We thank Rod Peakall for assistance with GenAlEx, Annette Usher and Emma Pharo for assistance with sample collection and mapping, Paul Sunnucks for suggesting the Mantel test approach and Gordon Luikart for comments on the manuscript. The NSW National Parks and Wildlife Service and Environment Australia provided scientific research permits. Financial support was provided by Australian Research Council (ARC) research grants to DJA and RJW and an ARC Postdoctoral Fellowship to PRE. Research support was also provided by the Institute for Conservation Biology at the University of Wollongong. This is contribution No. 213 from the Ecology and Genetics Group at the University of Wollongong.

\section{References}

Ayre DJ, Whelan RJ, Reid A (1994). Unexpectedly high levels of selfing in the Australian shrub Grevillea barklyana (Proteaceae). Heredity 72: 168-174.

Berg EE, Hamrick JL (1995). Fine scale genetic structure of a turkey oak forest. Evolution 49: 110-120.

Bonnin I, Ronfort J, Wozniak F, Olivieri I (2001). Spatial effects and rare outcrossing events in Medicago truncatula (Fabaceae). Mol Ecol 10: 1371-1383.

Briggs JD, Leigh JH (1996). Rare or Threatened Australian Plants. CSIRO, Melbourne.

Campbell DR, Dooley JL (1992). The spatial scale of genetic differentiation in a hummingbird-pollinated plant: comparison with models of isolation by distance. Am Nat 139: 735-748.

DeStefano S (2002) Regional and national issues for forest wildlife research and management. Forest Sci 48: 181-189.

Edwards W, Whelan RJ (1995). The size, distribution and germination requirements of the soil-stored seed bank of Grevillea barklyana (Proteaceae). Aust J Ecol 20: 548-555.

England PR, Ayre DJ, Whelan RJ (1999). Microsatellites in the Australian shrub Grevillea macleayana (Proteaceae). Mol Ecol 8: 689-690.

England PR, Beynon F, Ayre DJ, Whelan RJ (2001). A molecular genetic assessment of mating system variation in a naturally bird-pollinated shrub: contributions from birds and introduced honeybees. Conserv Biol 15: 1645-1655.

England PR, Usher AV, Ayre DJ \& Whelan RJ (2002) Microsatellite diversity and genetic structure of fragmented populations of the rare, fire-dependant shrub Grevillea macleayana. Mol Ecol 11: 967-977.

Epperson BK (1995). Spatial structure of two-locus genotypes under isolation by distance. Genetics 140: 365-375.
Epperson BK, Allard RW (1989). Spatial autocorrelation analysis of the distribution of genotypes within populations of lodgepole pine. Genetics 121: 369-377.

Gehring JL, Delph LF (1999). Fine scale genetic structure and clinal variation in Silene acaulis despite high gene flow. Heredity 82: 628-637.

Jackson SM, Fredericksen TS, Malcolm JR (2002). Area disturbed and residual stand damage following logging in a Bolivian tropical forest. Forest Ecol Manage 166: 271-283.

Kawata M (2001). The influence of neighborhood size and habitat shape on the accumulation of deleterious mutations. J Theor Biol. 211: 187-199.

Luikart G, England PR (1999). Statistical analysis of microsatellite DNA data. TREE 14: 253-256.

Makinson RO (1999). Grevillea. In: Flora of Australia. CSIRO Publishing, Melbourne, Vol. 17a.

McGarigal K, Romme WH, Crist M, Roworth E (2001). Cumulative effects of roads and logging on landscape structure in the San Juan Mountains, Colorado (USA). Landscape Ecol. 16: 327-349.

McGillivray DJ (1993). Grevillea. Melbourne University Press, Melbourne.

Peakall R, Smouse PE (2001). GenAlEx V5: Genetic Analysis in Excel. Population Genetic Software for Teaching and Research. Australian National University, Canberra, Australia. http:/ / www.anu.edu.au/BoZo/GenAlEx/

Raymond M, Rousset F (1995). GENEPOP (version 12): a population genetics software for exact tests and ecumenicism. J Hered 86: 248-249.

Smouse PE, Dyer RJ, Westfall RD, Sork VL (2001). Twogeneration analysis of pollen flow across a landscape. I. Male gamete heterogeneity among females. Evolution 55: 260-271.

Smouse PE, Peakall R (1999). Spatial autocorrelation analysis of individual multiallele and multilocus genetic structure. Hered 82: 561-573.

Streiff R, Labbe T, Bacilieri R, Steinkellner H, Glossi J, Kremer A (1998). Within population genetic structure in Quercus robur. L and Quercus petraea (Matt.) Liebl. Assassed with isozymes and microsatellites. Mol Ecol 7: 317-328.

Ueno S, Tomaru N, Yoshimaru H, Manabe T, Yamamoto S (2000). Genetic structure of Camellia japonica L. in an oldgrowth evergreen forest, Tsushima, Japan. Mol Ecol 9: 647656.

Vaughton G (1995). No evidence for selective fruit abortion in the Australian shrub Grevillea barklyana (Proteaceae). Int J Plant Sci 156: 417-424.

Vaughton G (1996). Pollination disruption by European honeybees in the Australian bird-pollinated shrub Grevillea barklyana (Proteaceae). Plant Sys Evol 200: 89-100.

Vaughton G (1998). Soil seed bank dynamics in the rare, obligate seeding shrub, Grevillea barklyana (Proteaceae). Aust J Ecol 23: 375-384.

Whelan RJ, Ayre DJ, England PR, Llorens TM, Beynon F (2000) Population fragmentation and the ecology and genetics of Grevillea (Proteaceae). In: Young A, Clarke G (eds) Genetics, Demography and the Viability of Fragmented Populations, Cambridge University Press: Cambridge.

Wright S (1969). Evolution and the Genetics of Populations. The Theory of Gene Frequencies, Vol 2. University of Chicago Press: Chicago. 